\section{Commentary: Bronchial anastomosis for lung transplantation-one suture fits all}

\author{
Stephanie H. Chang, MD, and Zachary N. Kon, MD
}

Airway anastomotic complications remain a source of morbidity and mortality after lung transplantation. Rates of postoperative bronchial complications have decreased over time, but there is still a high incidence ranging from $2 \%$ to $25 \%{ }^{1,2}$ This decrease can be attributed to improvements in technique, such as shortening the donor bronchus and using absorbable suture. However, there remain a variety of anastomotic implantation techniques, such as continuous running suture with a single suture or 2 sutures, or running the membranous portion of the airway and interrupting the cartilaginous surface. ${ }^{1,3}$ Some institutions prefer running suture for size-matched donor and recipient bronchi but using interrupted cartilaginous sutures when there is appreciable mismatch $^{3}$ or lobar transplantation to minimize postoperative bronchial complications.

The authors of this study have been proponents of single continuous running bronchial anastomosis for lung transplantation in all situations, including size mismatch, single-lung transplantation, and lobar transplantation. ${ }^{4}$ Examining their data over an 18-year period, there was a low complication rate of $1.56 \%$, with 2941 anastomoses in 1555 patients. They defined an anastomotic complication as patients who required any endoscopic or surgical intervention postoperatively and was graded according to the International Society of Heart and Lung Transplantation classification system. ${ }^{5}$ A majority of their complications were stenosis (42/45), with only $0.1 \%$ dehiscence and $0.03 \%$ necrosis rates. Interestingly, there was a greater

\footnotetext{
From the Department of Cardiothoracic Surgery, New York University Langone Health, New York, NY.

Disclosures: Dr Kon is a consultant for Medtronic, Inc, and Breethe, Inc. Dr Chang has nothing to disclose with regard to commercial support

Received for publication Jan 23, 2020; accepted for publication Jan 26, 2020; available ahead of print Feb 7, 2020.

Address for reprints: Stephanie H. Chang, MD, Division of Thoracic Surgery, Department of Cardiothoracic Surgery, New York University Langone Health, 530 First

Ave, Suite 9V, New York, NY 10016 (E-mail: stephanie.chang@nyulangone.org). J Thorac Cardiovasc Surg 2020;160:1109-10

$0022-5223 / \$ 36.00$

Copyright (c) 2020 by The American Association for Thoracic Surgery

https://doi.org/10.1016/j.jtcvs.2020.01.067
}

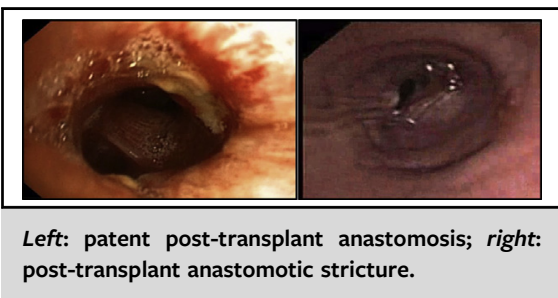

CENTRAL MESSAGE

Single running suture for bronchial anastomoses in lung trans-

plant is a good technique, with a low incidence of bronchial complications at a high-volume center.

rate of right-sided anastomotic complications $(2.44 \%$ for right anastomoses vs $0.68 \%$ for left anastomoses), which correlates to data from other groups and perhaps highlights the susceptibility of the right bronchial blood supply. Lobar anastomoses did not have a greater rate of postoperative complications at the lobar anastomotic site, with $1.72 \%$ $(5 / 290)$ requiring intervention. Their overall low rate, which additionally decreased over time from $2.4 \%$ from 1999 to 2003 to $0.8 \%$ from 2014 to 2017 , demonstrates that, in the correct hands, single-suture running anastomoses can be used ubiquitously in lung transplant bronchial anastomoses.

This retrospective study demonstrates the feasibility of using a single running suture technique with low anastomotic complications for lung transplant, including greaterrisk anastomoses. However, these data are generated from a high-volume group that has used this one technique for nearly 2 decades. The single running suture should be considered another method for bronchial anastomoses, but the other previously described options of continuous running suture with 2 sutures or running the membranous portion of the airway and interrupting the cartilaginous rings are also appropriate. The choice of anastomosis should remain dependent on the judgment of the surgeon, with this technique as another tool in their armamentarium.

\section{References}

1. Aigner C, Jaksch P, Seebacher G, Neuhauser P, Marta G, Wisser W, et al. Single running suture - the new standard technique for bronchial anastomoses in lung transplantation. Eur J Cardiothorac Surg. 2003;23:488-93.

2. Herrera JM, McNeil KD, Higgins RS, Coulden RA, Flower CD, Nashef SA, et al Airway complications after lung transplantation: treatment and long-term outcomes. Ann Thorac Surg. 2001;71:989-93.

3. Puri V, Patterson GA. Adult lung transplantation: technical considerations. Semin Thorac Cardiovasc Surg. 2008;20:152-64. 
4. Schweiger T, Nenekidis I, Stadler JE, Schwarz S, Benazzo A, Jaksch P, et al. Single running suture technique is associated with a low rate of bronchial complications after lung transplantation. J Thorac Cardiovasc Surg. 2020;160: 1099-108.e3.
5. Crespo MM, McCarthy DP, Hopkins PM, Clark SC, Budev M, Bermudez CA, et al. ISHLT consensus statement on adult and pediatric airway complications after lung transplantation: definitions, grading system, and therapeutics. J Heart Lung Transplant. 2018;37:548-63.
See Article page 1099.

\section{Commentary: Running bronchial anastomotic suture in lung transplantation: Should we run before we walk?}

\author{
Jules Lin, MD
}

Schweitzer and colleagues ${ }^{1}$ report a large series of 1555 patients undergoing lung transplant using a single running suture bronchial anastomotic technique. Although many surgeons are hesitant to use a running suture due to the risk of purse-stringing and narrowing the anastomosis, the authors should be congratulated on achieving excellent results with a low rate of anastomotic complications. These complications have decreased over time, and the majority were treated endoscopically.

Including patients over almost 2 decades allowed the authors to create a larger study cohort, but the long time period introduces potential confounding issues. Changes in lung transplant selection and allocation (eg, distance, primary disease group, disease severity, and functional status), anastomotic and operative technique (eg, donor bronchial length, extracorporeal membrane oxygenation [ECMO], or cardiopulmonary bypass), donor procurement (eg, donation after cardiac death, retrograde perfusion, preservation solutions, or ex vivo lung perfusion [EVLP]), postoperative care, and immunosuppression (induction therapy) could all potentially affect the incidence of anastomotic complications.

In the current study, the disease group, use of ECMO intraoperatively and as a bridge-to-transplant, and EVLP

From the Section of Thoracic Surgery, Department of Surgery, University of Michigan Medical Center, Ann Arbor, Mich.

Disclosure: Author has nothing to disclose with regard to commercial support.

Received for publication March 1, 2020; accepted for publication March 3, 2020; available ahead of print March 19, 2020.

Address for reprints: Jules Lin, MD, Section of Thoracic Surgery, Department of Surgery, University of Michigan Medical Center, 1500 E Medical Center Dr, 2120TC/ 5344, Ann Arbor, MI 48109-5344 (E-mail: juleslin@umich.edu).

J Thorac Cardiovasc Surg 2020;160:1110-1

$0022-5223 / \$ 36.00$

Copyright (c) 2020 by The American Association for Thoracic Surgery

https://doi.org/10.1016/j.jtcvs.2020.03.022

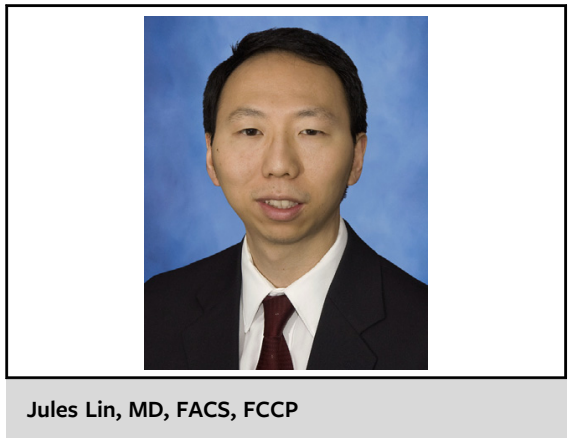

CENTRAL MESSAGE

Although many surgeons hesi-

tate to use a single running su-

ture bronchial anastomotic

technique, this large series re-

ports a low rate of bronchial

changed signif-

complications.

icantly over time. However, there was no association between ECMO or EVLP and bronchial complications, and the authors believe that the lower complication rate during the later time periods was due to increasing experience and transplant volumes. Anastomotic complications were higher with antithymoglobulin and with no induction therapy, and the majority of these patients were transplanted in the earlier time periods. Those treated with antithymoglobulin or without induction received higher doses of corticosteroids during the first year, which has been associated with anastomotic complications.

Anastomotic complications were higher with lobar transplants with 7 of the 45 airway complications in the lobar group. The incidence for anastomotic complications was $3.3 \%$ (7 out of 212) after lobar transplant, and all were right-sided. Mitilian and colleagues ${ }^{2}$ also found a higher anastomotic complication rate, with $16 \%$ requiring endoscopic treatment. In addition, airway complications may have a greater influence on the outcomes of lobar lung transplant recipients. ${ }^{3}$ 